\title{
Evaluating the Bilateral Government Guarantee Value in PPP Highway Projects
}

\author{
Min Qin ${ }^{1, a}$ and Xiaodong $\mathrm{Wu}^{1, \mathrm{~b}^{*}}$ \\ ${ }^{1}$ Zhejiang University,Hangzhou, Zhejiang P.R.China, \\ a276025901@qq.com , bwuxiaodongjx@163.com
}

\begin{abstract}
Keywords: Public-private-partnership(PPP); Real option; Government guarantees; Traffic volume; Game theory
\end{abstract}

\begin{abstract}
Governments around the world are increasingly focusing on private investment in the infrastructure sector through PPP framework, and are no exception in the area of transport infrastructure. To reduce the risk to the investors, governments used to provide guarantees and other forms of support. These guarantees can be analyzed by some real options, and it is very valuable but easy to be overlooked. In this paper, PPP project's value contain not only the project's NPV, but also real options value implied in the project. Models about government guarantees in PPP highway projects have been proposed: a minimum traffic guarantee and a maximum traffic guarantee. The game theory approach has also been introduced to help the distribution of risks between government and private investors. It is necessary to use methodology to value the project investments and dig the potential value.
\end{abstract}

\section{Introduction}

Countries around the world are currently encouraging the development of PPP in the field of infrastructure, in this wave of strong encouragement of PPP mode, PPP mode of operation and development led to a wide range of social concerns. In view of the uncertainties embedded in large scale investments and long recovery cycles, investors and other stakeholders in PPP projects generally bear serious risks, including political risks, construction risks, market risks, credit risks and operational risks[1].

In the actual operation process, the highway PPP proje ct social capital access threshold is high, the investment is big, the license period is long, but also lacks the practical experience and the operation mode, as well as also causes the decision mistake, the technology is immature and so on Factors, social capital will be worried about the toll road can be profitable on the PPP model hesitated, Governments can make such projects viable by offering guarantees and subsidies under certain conditions and offering tax incentives under other conditions.[2]In this time the government often take "commitment" approach, if the actual traffic income does not reach the minimum traffic demand should be income Will give a certain financial subsidy. At the same time, in order to prevent the social capital because of the "monopoly" project causes the investor's profits and deviate from the public transport infrastructure services to the public, the government will ask when the actual traffic income is higher than the agreed excess amount of the maximum amount of excess, To the excess returns to give a certain distribution, fully embodies the principle of risk sharing and benefit sharing, so that investors "profit and not profiteering."[3]

Thus, whether the government's "commitment" or "distribution" of excess returns can be considered as an option, the government and the private sector have a certain value of the option, the private sector to determine whether the investment and government "Commitment" before, need to be assessed. For the government, the assessment of this commitment can be chosen to bring high social benefits of investors, but also early warning of financial risks, and for the private sector, is conducive to making the right risk analysis, to estimate the actual project Value, and thus make the right investment decisions. [4]

The evaluation of the investment value of PPP high project is mainly divided into two parts. The first part is to consider the NPV value under the uncertainty of traffic volume, the second part is to 
calculate the real option value[5]. Therefore, in the assessment process, it is divided into the following process to calculate: to predict the traffic flow of the expressway; Calculate the net present value under the condition of uncertain traffic volume; calculate the value of real options; check and analyze the results; re-design if necessary.[6]

\section{Research on the Investment Value of PPP Highway Project under the Government Guarantee}

Minimum Traffic Guarantee. As China has now explicitly prohibit the local government to invest in infrastructure investment to do the minimum guarantee, so the domestic highway projects in the highway PPP, the government is to take the minimum amount of traffic guarantee in the form of the minimum proceeds of the guarantee, This is the use of government viable gap subsidies to form the government's lowest yield guarantee. This is a guarantee of the traffic flow that occurs when the expressway PPP project traffic does not reach a certain percentage of the expected minimum traffic flow, the government undertakes a percentage of the standard vehicle traffic forecast in the feasibility study report, To be a certain subsidy. Through the establishment of the government viability gap adjustment dynamic adjustment formula to establish the government feasibility gap between subsidies and certain specific indicators (such as the actual charges, the actual traffic) of the linkage between the government and social capital to share the risk And share profits. In fact, dealing with the uncertainty of traffic in such an agreement under the formation of a European put option, from the investor's terms, the put option, an increase of the project's investment value.

Table 1 Option Characteristics about the government minimum traffic volume guarantee[7]

\begin{tabular}{|c|c|}
\hline Option feature & Minimum traffic guarantee \\
\hline Option type & European put option \\
\hline Underlying asset & traffic \\
\hline Execution price & Lower traffic volume \\
\hline Maturity date & At the end of each operation \\
\hline Fluctuation rate & Fluctuation rate of traffic \\
\hline Risk free interest rate & Risk free interest rate \\
\hline
\end{tabular}

The government subsidy received by the investor every year is:

$$
G R_{t}=y_{1} \cdot P_{t} \operatorname{Max}\left(m_{1} \bar{R}_{t}-R_{t}, 0\right)
$$

$\mathrm{y}_{1}$ is the percentage of the government's minimum traffic subsidy for the investor, $\mathrm{P}_{\mathrm{t}}$ is the prevailing unit price in the year $\mathrm{t}, \mathrm{m}_{1}$ is the government's minimum traffic guarantee proportion factor, $\bar{R}_{t}$ is the expected traffic volume for year $\mathrm{t}$, and $\mathrm{R}_{\mathrm{t}}$ is the actual traffic volume for year $\mathrm{t}$.

the Black-Scholes model can be used to calculate the government's minimum traffic guarantee option value because the government is implementing a minimum-cost European-style guarantee option at the end of each year.

$$
\begin{aligned}
& G R_{t}=y_{1} P_{t}\left[m_{1} \bar{R}_{t} e^{-r t} N\left(-d_{2}\right)-\mathrm{R}_{\mathrm{t}} e^{(\partial-\lambda-\lambda-r) t} N\left(-d_{1}\right)\right] \\
& d_{1}=\frac{\ln \left(\frac{R_{t}}{m_{1} \bar{R}}\right)+\left(\alpha-\lambda \sigma+\frac{\sigma^{2}}{2}\right) t}{\sigma \sqrt{t}}, d_{2}=d_{1}-\sigma \sqrt{t}
\end{aligned}
$$

Where $\mathrm{N}(*)$ is the cumulative probability distribution function for the standard normal distribution

Maximum Traffic Guarantee. In ensuring the minimum amount of traffic guarantees, the Government will often set a ceiling on the total amount of the private sector in the public interest, which is often a bilateral guarantee. That is, if the actual traffic volume of the PPP project in the 
operating period is higher than that in the feasibility study report, the government allocates the excess traffic volume according to the distribution ratio stipulated in the contract and the social capital , For investors, this time also has a bearish real option value.[8]

Table 2 Option Characteristics about the government maximum traffic volume guarantee

\begin{tabular}{|c|c|}
\hline Option feature & Maximum traffic guarantee \\
\hline Option type & European call option \\
\hline Underlying asset & traffic \\
\hline Execution price & Upper traffic volume \\
\hline Maturity date & At the end of each operation \\
\hline Fluctuation rate & Fluctuation rate of traffic \\
\hline Risk free interest rate & Risk free interest rate \\
\hline
\end{tabular}

$$
R R_{t}=-y_{2} \cdot P_{t} \operatorname{Max}\left(R_{t}-m_{2} \bar{R}_{t}, 0\right)
$$

where, $y_{2}$ is the percentage of the government to participate in the distribution of excess traffic volume, $\mathrm{P}_{\mathrm{t}}$ is the $\mathrm{t}$-year toll, $\mathrm{m}_{2}$ is the excess traffic ratio factor, $\bar{R}_{t}$ is the expected annual traffic volume, $R_{t}$ is the actual traffic volume in the first year.

Since the government is a guarantee option to carry out excess traffic at the end of each year, the Black-Scholes model can be used to calculate the value of the government's excess traffic option.[9]

$$
\begin{aligned}
& R R_{t}=-y_{2} P_{t}\left[R_{t} e^{(\partial-\lambda o-r) t} N\left(d_{1}\right)-m_{2} \overline{\mathrm{R}_{t}} e^{-r t} N\left(d_{2}\right)\right] \\
& d_{1}=\frac{\ln \left(\frac{R_{t}}{m_{2} \bar{R}}\right)+\left(\alpha-\lambda \sigma+\frac{\sigma^{2}}{2}\right) t}{\sigma \sqrt{t}}, d_{2}=d_{1}-\sigma \sqrt{t}
\end{aligned}
$$

Where $\mathrm{N}(*)$ is the cumulative probability distribution function for the standard normal distribution

\section{Study on Compound Option Value Based on Bargaining Game}

The Bargaining Model Based on Option Value Calculation. The cost of the minimum traffic guarantee value and the maximum traffic guarantee value model of the PPP project based on the real option has been obtained. The PPP project emphasizes the sharing of the risk of the government and the private sector, emphasizing that both parties have the right to participate in the risk sharing Of the negotiations[10]. In the following, we introduce the bargaining game model, consider the different preferences of the government, discuss the percentage of the government's minimum traffic subsidy $\mathrm{y}_{1}$ and the percentage $\mathrm{y}_{2}$ given by the investor to the government to participate in the distribution of excess traffic. Although the bargaining game can theoretically, Both the government and the investor are satisfied, but taking into account the negotiating costs that both parties need to pay, we only discuss the three-stage bargaining game model, and then design the corresponding traffic risk sharing strategy, given the investor to participate in the PPP project investment for reference. Therefore, the following three-stage bargaining model is used to construct the government's lowest traffic guarantee option value distribution model, so as to help the investors to consider the government's risk appetite, which is helpful to estimate the actual value of the project and make accurate investment decision.

According to the bargaining game model, we can get government departments and private organizations a unique Nash equilibrium:

In the bargaining model, the first party has a negotiating advantage, taking into account the fact that the government tends to take the initiative in the negotiation of the actual PPP project, so the government is the ultimate decision maker of the negotiations, regardless of the outcome of the negotiations. 


$$
\begin{aligned}
& P_{01}=\frac{\delta_{2}\left(1-\delta_{1}\right)}{1-\delta_{1} \delta_{2}} \quad P_{02}=\frac{1-\delta_{2}}{1-\delta_{1} \delta_{2}} \\
& \delta_{1}=\frac{1}{1+\mathrm{S}_{1}}, \quad \delta_{2}=\frac{1}{1+\mathrm{S}_{2}}
\end{aligned}
$$

$S_{1}$ and $S_{2}$ are the risk preference coefficient (risk rate of return), and different governments have different risk preferences when encountering different highway PPP projects. In the case of different risk preferences, the corresponding willingness to bear the risk ratio is not the same, this time, investors will take into account the risk of sharing and income, adjust the willingness to bear the risk ratio. Into the risk factor, the government and the investor's risk-sharing ratio is:

$$
\begin{gathered}
P_{01}=\frac{S_{1}}{S_{1}+S_{2}+S_{1} S_{2}} \\
P_{02}=\frac{S_{1}+S_{1} S_{2}}{S_{1}+S_{2}+S_{1} S_{2}}
\end{gathered}
$$

Guaranteed Real Option Value Based on Bargaining Game Model . Taking into account the risk of the PPP project on the highway, the private sector often requires the government to provide the minimum traffic guarantee. During the concession period, when the actual traffic is below the government's minimum traffic guarantee, the government will, in theory, The full amount of compensation in the department, that is, the calculated real option value of the minimum traffic guarantee, the smaller the traffic volume, the greater the value of the government guarantee. When the actual traffic is greater than the minimum traffic volume, then the government's guarantee value is 0 .

In the PPP project of the highway, the government's guarantee of the minimum traffic volume provided by the private sector is essentially the risk of sharing the project operation. While this guarantee is only a commitment by the government to deal with the risks of the private sector in the future, the government assumes full market risk when the actual traffic is below the agreed minimum, and if it is not adequately assessed, it will give government finances Bring great pressure. The traditional theory that both the private sector and government departments are risk aversion, that are unwilling to take risks. Government departments in doing the minimum traffic guarantee time, will also take into account their own risk, based on their own risk appetite to give the appropriate government compensation. In the actual situation, the market demand is uncertain, the government must consider how to fully mobilize the private sector operation and maintenance of highway PPP project initiative, when faced with the reasons for the private sector itself (such as highway construction quality is poor, improper maintenance) and When the amount of traffic is reduced, the government has the right to require the private sector to share the corresponding risks. At this point, the government's minimum guaranteed value will take into account the risk-sharing and value distribution issues, the Government is not to provide a complete guarantee, the Government only bear part of the risk, not the full risk. The value of the real option of the government's minimum vehicle traffic secured by the private sector will be discounted accordingly, which should also be taken by the private sector in assessing the value of the PPP project on the highway. The corresponding risk should also be In the private sector can bear the risk range, in line with the private sector risk appetite, so as to achieve the government and the private sector are relatively acceptable conditions, otherwise the two sides can not reach an agreement, resulting in the failure of PPP projects. In traditional investment projects, the government will directly according to the actual situation to give the risk of distribution, on their own risk appetite to give the appropriate government compensation.

When the risk assumed by the government is $\mathrm{P}_{01}$, considering the risk appetite of the government and the investor, the minimum traffic guarantee value obtained by the investor at this time is: 


$$
G R_{t}=\frac{S_{1}}{S_{1}+S_{2}+S_{1} S_{2}} P_{t}\left[m_{1} \overline{\mathrm{R}}_{\mathrm{t}} e^{-r t} N\left(-d_{2}\right)-\mathrm{R}_{\mathrm{t}} e^{(\partial-\lambda \sigma-r) t} N\left(-d_{1}\right)\right]
$$

Excerptive Real Option Value Based on Bargaining Game Model. When the risk of the government is $\mathrm{P}_{01}$, the corresponding investor assumes the risk of $\mathrm{P}_{02}$. Since the investor has the minimum return guarantee the real option value, the government should also have the value of the excess return if the investor returns too much Participate in the corresponding allocation. The distribution ratio should be the proportion of the government to assume the risk of distribution, accordingly, the investor's excess returns real value should be:

$$
R R_{t}=-\frac{S_{2}+S_{1} S_{2}}{S_{1}+S_{2}+S_{1} S_{2}} P_{t}\left[R_{t} e^{(\partial-\lambda \sigma-r) t} N\left(d_{1}\right)-m_{2} \overline{\mathrm{R}_{\mathrm{t}}} e^{-r t} N\left(d_{2}\right)\right]
$$

\section{The 0ption Value Acquired by the Investor}

Compound Option Value Model Based on Government Bilateral Guarantee. During the entire project period, the investor buys the put option, sells the call option, the increase in the value of the item obtained is the sum of the European put and call options due to the bilateral guarantees of the government, ie the minimum traffic guarantee value and excess traffic The sum of the value of the value, the guarantee period in the entire concession period as follows:

$$
\begin{aligned}
& A V=\sum_{t=k}^{T} G R_{t}+\sum_{t=k}^{T} R R_{t} \\
& =\sum_{t=k}^{T} \mathrm{y}_{1} \cdot P_{t} \operatorname{Max}\left(m_{1} \bar{R}_{t}-R_{t}, 0\right)-\sum_{t=k}^{T} y_{2} \cdot P_{t} \operatorname{Max}\left(R_{t}-m_{2} \bar{R}_{t}, 0\right)
\end{aligned}
$$

\section{Compound Option Value Model with Different Income Distribution and Different}

Government Guarantee Level. The three-stage bargaining game model is introduced, and the guaranteed value obtained by the investor during the operation period is:

$$
\begin{aligned}
\mathrm{AV}= & \frac{\mathrm{S}_{1}}{S_{1}+S_{2}+S_{1} S_{2}} \sum_{t=k}^{T} \cdot P_{t} \operatorname{Max}\left(m_{1} \overline{R_{t}}-R_{t}, 0\right)-\frac{S_{2}+S_{1} S_{2}}{S_{1}+S_{2}+S_{1} S_{2}} \sum_{t=k}^{T} P_{t} \operatorname{Max}\left(R_{t}-m_{2} \bar{R}_{t}, 0\right) \\
= & \frac{S_{1}}{S_{1}+S_{2}+S S_{2}} P_{t}\left[m_{1} \bar{R}_{t} e^{-r t} N\left(-d_{2}\right)-\mathrm{R} e^{(\partial-\lambda \sigma-r) t} N(-d)_{1}\right] \\
& \left.-\frac{S_{2}+S S_{2}}{S_{1}+S_{2}+S S_{2}} P_{t}\left[R_{t} e^{(\partial-\lambda \sigma-r) t} N d_{1}-\right) m_{2}-\mathbb{R}^{r t} N(d)_{2}\right]
\end{aligned}
$$

\section{Conclusion}

In the PPP project, the traffic volume of the expressway is a big factor influencing the investor's income. Due to the uncertainty of the traffic volume, the government often adopts the bilateral guarantee way to attract the investors to invest. In this paper, the Black-Scholes (B-S) model in real option is used to analyze the minimum traffic volume guarantee and excess benefit guarantee, and the game theory is introduced and the risk and benefit are discussed and distributed by the three-stage bargaining game. Better assessment of highway investment value, tap the investment potential has an important impact.

\section{Reference}

[1] Liu J, Yu X, Cheah C Y J. Evaluation of restrictive competition in PPP projects using real option 
approach[J]. International Journal of Project Management. 2014, 32(3): 473-481.

[2] Frances F. Blank T K N B. Private Infrastructure Investment through Public Private Partnership: An Application to a Toll Road Highway Concession in Brazil[Z]. 2009.

[3] Min Rui. Based on the real option of the minimum benefit of highway protection [D]. Dalian University of Technology, 2015.

[4] Jin Lulu.Study on excess return decision of highway BOT project based on real option [D]. Dalian University of Technology, 2015.

[5] Li Xiaohu.Study on investment value of road PPP project based on traffic guarantee [J]. Southwest Highway. 2015 (02): 105-109.

[6] Chen Haiyi. Government guarantees under the PPP infrastructure project value [D]. Shanghai: Tongji University, 2009.

[7] Wang Yinglin, Fu Meng, Lin Xiangqian. Evaluation of the Alternative Option Value of Government Guaranteed PPP Project [J]. Journal of Engineering Management. 2015 (1): 65-70.

[8] Shu Hao. Based on the real option of the PPP project government minimum product demand guarantee and income limit level decision [D]. Southwest Jiaotong University, 2013.

[9] Guo Jian. Highway infrastructure PPP project traffic risk sharing strategy research [J]. Management Review. 2013 (07): 11-19.

[10] Li Lin, Liu Zhihua, Zhang Kunchang. Game model of PPP project risk allocation under asymmetric conditions of participant status [J]. Journal of Systems Engineering and Practice. 2013, 33 (8): 1941-1948. 